\title{
Pengaruh LPF Orde Satu dan Dua pada Karakteristik PLL Menggunakan IC CD4046
}

\author{
Budihardja Murtianta ${ }^{1}$, JP Tirtayasa ${ }^{2}$, FD Setiaji $^{3}$ \\ 1,2,3Program Studi Teknik Elektro, \\ Fakultas Teknik Elektronika dan Komputer, \\ Universitas Kristen Satya Wacana, Salatiga \\ 1budihardja.murtianta@staff.uksw.edu, ${ }^{2} 612011010 @$ student.uksw.edu, ${ }^{3}$ fdsetiaji@gmail.com
}

\begin{abstract}
Ringkasan
Pada tulisan ini disampaikan hasil pengukuransistemPhase Locked Loop (PLL) menggunakan IC CD4046, dengan menggunakan dua macam tapis yaitu tapis lolos bawah (LPF)orde satu dan orde dua. Pengukuran yang dilakukan meliputi nilai frekuensi frekuensi maksimum dan minimum $V C O$ (Voltage Controlled Oscillator), lock range, capture range danpengaruh frekuensi penggal LPF terhadap karakteristikPLL. Hasil pengujian menunjukkan frekuensi penggal tapis yang makin besar cenderung memperbesar nilai capture range, sedangkan lock range tetap.
\end{abstract}

Kata kunci:PLL, CD4046, locked range, capture range, orde, tapis

\section{Pendahuluan}

PLL memiliki peranpenting dalam perkembangan sistem telekomunikasi. Aplikasi PLL meliputi Demodulasi FM, Demodulasi FSK, Tone Decoding, Frequency Multiplication, dan lain sebagainya. [1]

Sistem PLLtersebut sudah direalisasikan dalam berbagai bentuk rangkaian terpadu (IC). Yang akan direalisasikan pada makalah ini adalah dengan menggunakan IC CD4046 yang memiliki konsumsi daya rendah $(100 \mu \mathrm{W})$ sehingga cocok untuk aplikasi portabel.

Salah satu bagian PLL yang penting adalah $L P F$, yang digunakan untuk menekan derau dan komponen frekuensi tinggi dari Phase Detector $(P D)$ dan menghasilkan sinyal DC untuk masukan VCO. [2] Orde LPF yang digunakan akan mempengaruhi bandwidth PLL, dan LPF dengan orde lebih tinggi memiliki kemampuan menolak derau yang lebih baik [3].

\section{Dasar Teori}

\subsection{Prinsip Dasar PLL}

PLL adalah suatu sistem yang memungkinkan suatu sinyal dengan frekuensi acuan tertentu mengendalikan atau menyamakan nilai dari frekuensi sebuah osilator (dalam hal ini VCO) dalam sebuah lingkar umpan balik tertutup. Rangkaian PLL yang paling sederhana terdiri dari tiga modul, yaitu $V C O, P D$, dan $L P F$ seperti ditunjukkan Gambar 1 berikut ini. 


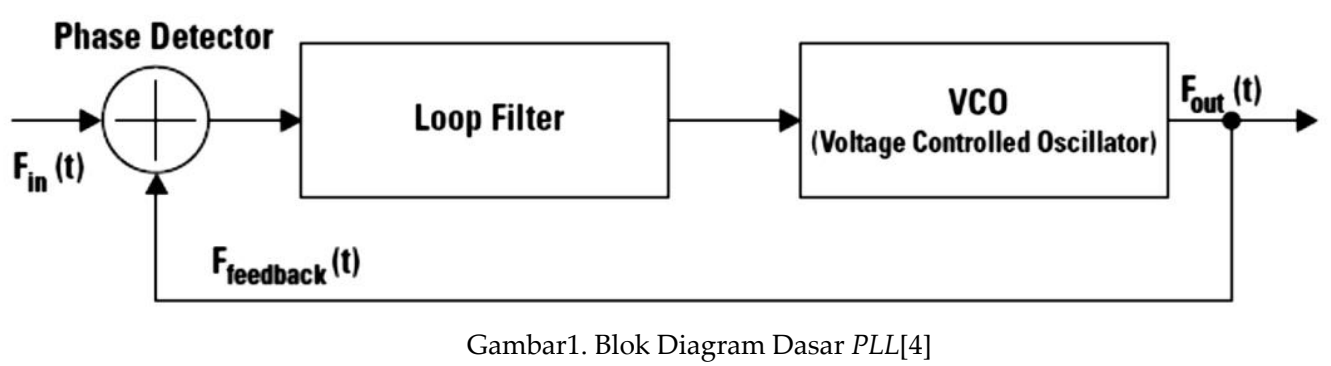

Frekuensi $f_{i}$ yang dihasilkan misalnya oleh suatu osilator referensi diumpankan ke rangkaian $P D$ untuk dibandingkan dengan frekuensi $f_{0}$ keluaranVCO. Misalkan kondisi awal $f_{i} \neq f_{o}$. Karena ada perbedaan frekuensi antara $f_{i}$ dan $f_{o}$, maka rangkaian $P D$ akan menghasilkan tegangan keluaran berubah waktu yang aperiodik yang kemudian dilewatkan LPF agar menjadi tegangan DC sebagaimasukan VCO. Tegangan DC ini menyebabkan rangkaian $V C O$ menghasilkan perubahan nilai $f_{o}$ sampai dicapai $f_{i}=f_{o}$ dan PLL disebut dalam kondisi terkunci (locked).

Pada IC CD4046, keluaran VCO berbentuk tegangan kotak DC dengan daur aktif $50 \%$. Ketika nilai $f_{i}=f_{o}$, maka selisif fase antara $P D$ dan $V C O$ bernilai konstan. Jika setelah terkunci nilai frekuensi $f_{i}$ berubah, maka tetap berlaku $f_{i}=f_{o}$ sampai nilai $f_{i}$ berada di luar jangkauan lock range. Parameter dalam sistem PLL antara lain:

-Free running-frequency $\left(f_{f}\right)$ atau adalah frekuensi keluaran dari $V C O$ pada saat tidak ada sinyal masukan pada PLL. Nilainya setengah dari nilai frekuensi maksimum yang dapat dikeluarkan oleh PLL.

-Lock Range $\left(f_{L}\right)$ atau disebut juga daerah kuncian adalah rentang daerah frekuensi dimana PLL tersebut masih tetap dapat mengikuti nilai frekuensi masukan, setelah kondisi terkunci dicapai.

- Capture Range $(f c)$ atau disebut juga daerah tangkapan adalah suatu daerah rentang frekuensi dimana sistem PLL mampu mengunci frekuensi apabila pada awalnya sistem tersebut tidak terkunci.

-Lock-up Time $(L c)$ atau disebut juga waktu penguncian adalah selang waktu transien yang dibutuhkan sistem, dari saat sistem tersebut dimulai sampai ke kondisi terkunci.

\subsection{IC PLL CD4046}

IC PLL CD4046 berisi bagian-bagian utama dari PLL yaitu VCO dan PD, sehingga untuk melengkapinya tinggal dipasang LPF dan pembagi frekuensi (:N) jika akan diterapkan dalam aplikasi frequency sinthesizer seperti ditunjukkan Gambar 2. 


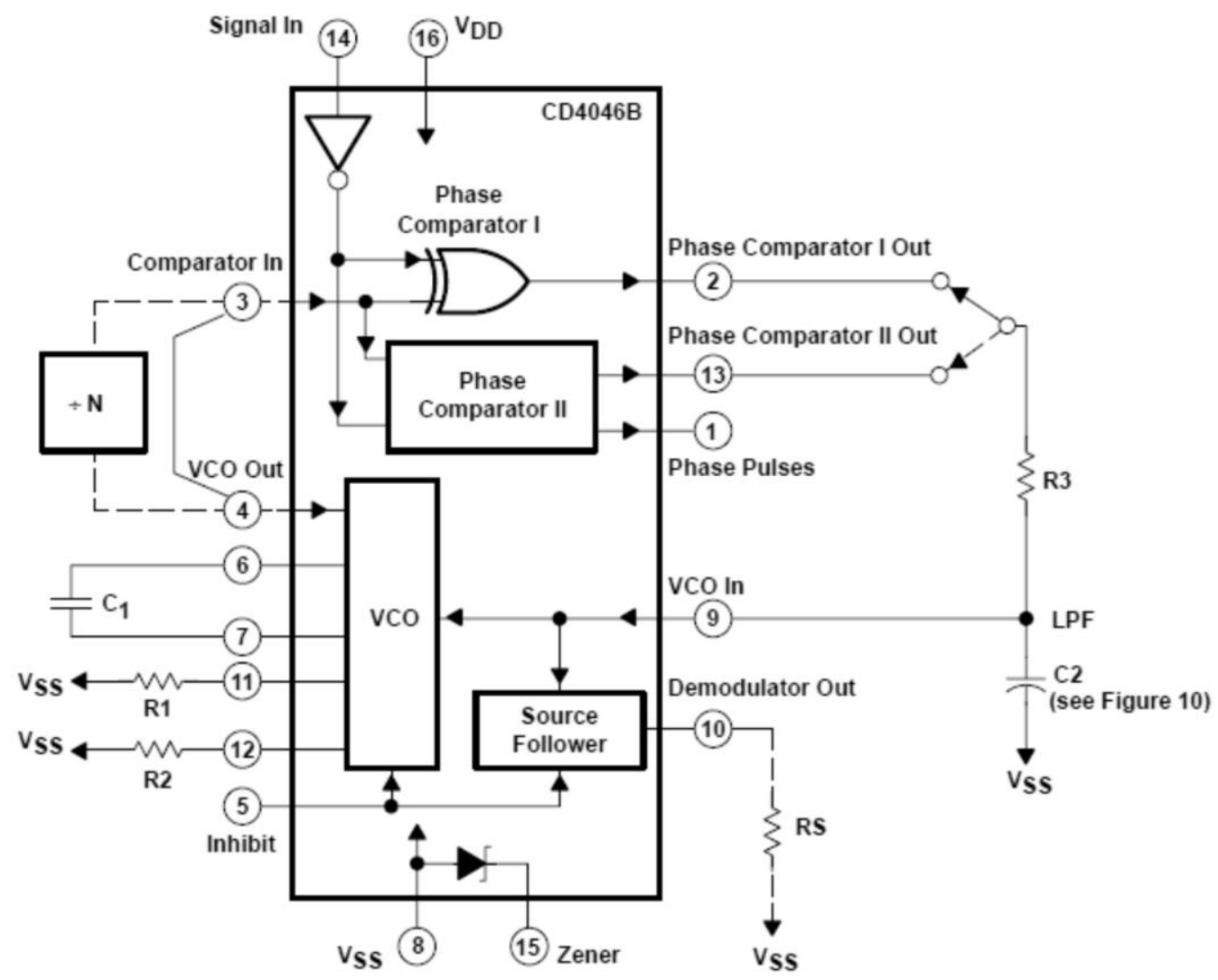

Gambar 2. Blok Diagram Dasar IC CD4046 [1]

Dalam IC tersebut terdapat dua macam $P D$ yaitu Tipe I dan Tipe II. $P D$ tipe I yang digunakan digunakan dalam makalah ini adalah berupa gerbang EXOR yang memiliki karakteristik keluaran sesuai Gambar 3.

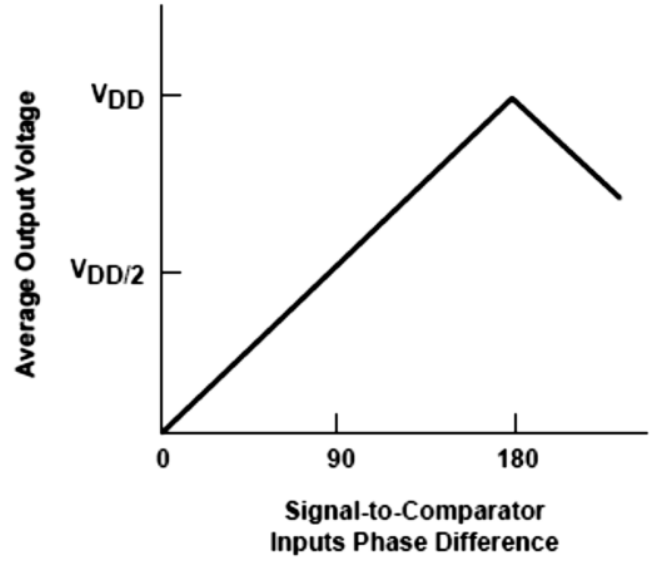

Gambar 3. Phase Detector tipe I pada IC CD4046 [1] 
Pada tidak ada sinyal masukan dan pin 3 dihubungkan langsung ke pin 4, keluaran $P D$ tipe I akan sama dengan keluaran $V C O$ yang berupa tegangan kotak $D C$ dengan amplitude $V D D$ dan daur aktif $50 \%$, oleh sebab itu tegangan reratanya sebesar $\mathrm{VDD}_{\mathrm{DD}}$ 2. Jika ada sinyal masukan dengan daur aktif $50 \%$, maka beda fase antara keluaran $V C O$ dan sinyal masukan tersebut berada dalam rentang $0^{\circ}$ sampai $180^{\circ}$.

Bentuk gelombang tipikal pada saat PLL terkunci ditunjukkan Gambar 4.

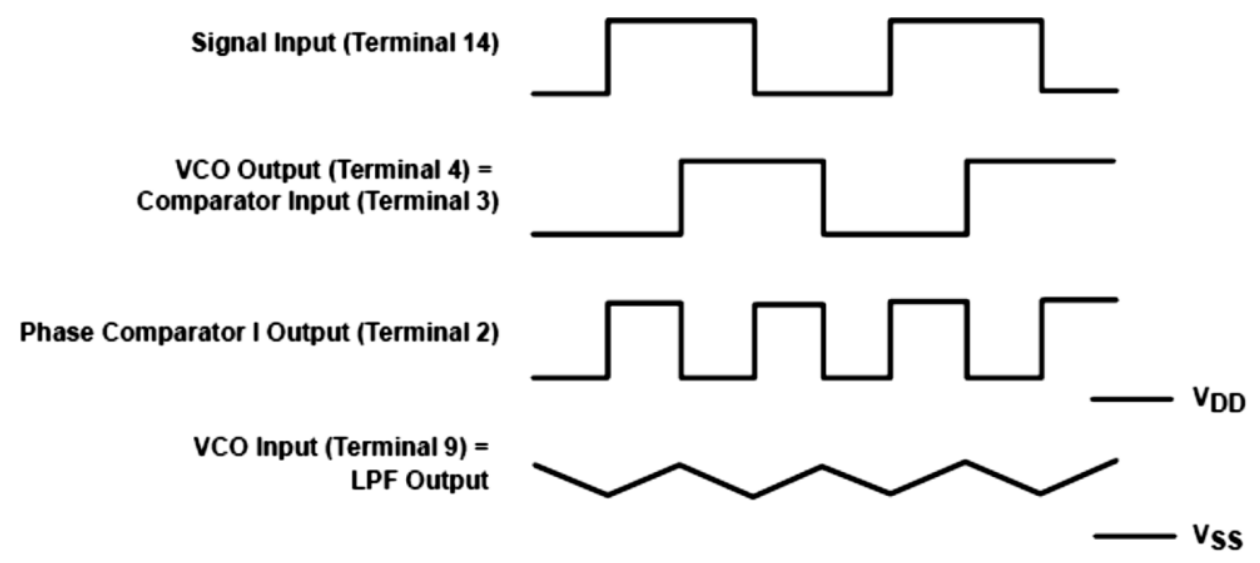

Gambar 4. Bentuk gelombang tipikal pada saatPLLIC CD4046 terkunci[1]

Keluaran $L P F$ akan berupa tegangan $D C$ tak murni yang memiliki komponen frekuensi tinggi yang tidak bisa dihilangkan sepenuhnya oleh tapis tersebut. Besarnya riak (ripple) akan tergantung pada orde LPF yang dipakai, yang dalam makalah ini digunakan LPF orde satu dan dua.

\section{Realisasi PLL Berbasis CD4046}

Rangkaian PLL dengan LPF orde satu berbasis CD 4046 mengacu ke Gambar 2 dengan nilai-nilai frekuensi penggal akan dijelaskan kemudian. Sedangkan untuk PLL dengan tapis orde dua, maka tapis diganti dengan rangkaian sebagai berikut ini.

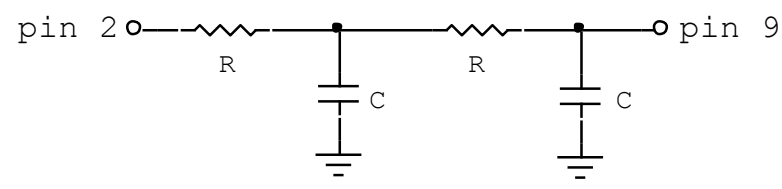

Gambar 5. LPF orde dua yang digunakan pada PLL CD4046

Frekuensi penggal $\left(f_{\mathrm{P}}\right)$ LPF orde satu pada Gambar 2:

$$
f_{\mathrm{P}}=\frac{1}{2 \pi R_{3} C_{2}}
$$

Sedangkan frekuensi penggal $\left(f_{\mathrm{P}}\right) L P F$ orde dua pada Gambar 5:

$$
f_{\mathrm{P}}=\frac{0,0595}{R C}
$$


Rentang frekuensi keluaran VCOIC CD4046 saat keluaran masih linear terhadap tegangan masukannya, dihitung menggunakan rumus sebagai berikut ini. [5]

$$
\begin{aligned}
& f_{\text {Min }}=\frac{K_{1}}{R_{2}\left(C_{1}+32 p F\right)} \\
& f_{\text {Max }}=f_{\text {Min }}+\frac{K_{2}}{R_{1}\left(C_{1}+32 p F\right)}
\end{aligned}
$$

Konstanta $K_{1}$ dan $K_{2}$ didapatkans ecara eksperimental.

Nilai kepekaan frekuensi (Ko) dari VCOtersebut adalah:

$$
K_{\mathrm{O}}=\frac{f_{\mathrm{Max}}-f_{\mathrm{Min}}}{V_{\mathrm{Max}}-V_{\mathrm{Min}}}
$$

Dimana $V_{\text {Max }}-V_{\text {Min }}$ adalah rentang masukan frekuensi $V C O$ yang terkait.

Untuk pengoperasian yang tepat, nilai-nilai komponen harus berada pada batas-batas sebagai berikut : $10 \mathrm{k} \Omega \leq \mathrm{R}_{1} \leq 1 \mathrm{M} \Omega, 10 \mathrm{k} \Omega \leq \mathrm{R}_{2} \leq 1 \mathrm{M} \Omega$ dan $100 \mathrm{pF} \leq \mathrm{C}_{1} \leq 100 \mathrm{nF}$.

\section{Pengujian Sistem}

\subsection{Pengujian $\mathrm{VCO}$}

Pengujian pada $V C O$ dilakukan dengan meberikan tegangan $D C$ variabel pada pin 9 dan mengukur frekuensi keluaran VCO pada pin 4. Dipilih frekuensi tengah $10 \mathrm{kHz}$ dan jangkauan frekuensi $8 \mathrm{kHz} \sim 12 \mathrm{kHz}$ serta $\mathrm{V}_{\mathrm{DD}}=5 \mathrm{~V}$. Berdasarkan Persamaan (3) dan (4) dan pengukuran, didapatkan nilai $R_{1}=322 \mathrm{k} \Omega, R_{2}=190 \mathrm{k} \Omega$, dan $C_{1}=1 \mathrm{nF}$. Grafik frekuensi keluaran VCOterhadap tegangan masukannya ditunjukkan Gambar 6.

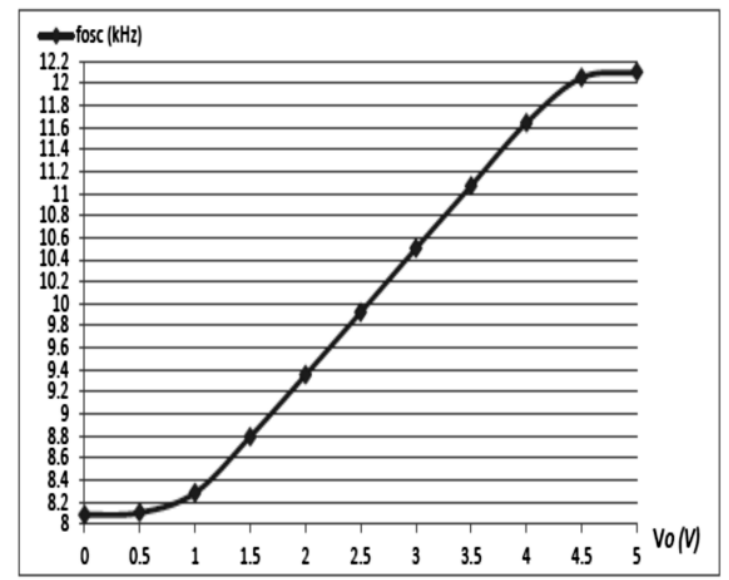

Gambar 6. Grafik frekuensi keluaran VCO terhadap tegangan masukannya

Dalam Gambar 6 tersebut terlihat bahwa nilai frekuensi keluaran VCO bersifat cukup linear terhadap tegangan masukannya dalam rentang $1,1 \mathrm{~V}$ sampai $4,3 \mathrm{~V}$ yang menghasilkan nilai kepekaan $V C O, K_{\mathrm{o}}=1,13(\mathrm{kHz} / \mathrm{V})$. 


\subsection{Pengaruh $L P F$ terhadap Karakteristik PLL CD 4046}

Pada pengukuran pertama, dilakukan pada PLL CD4046 dengan LPF orde satu (Gambar 2), dimana tegangan masukan adalah tegangan kotak $D C$ dengan amplitude $5 \mathrm{~V}$ dan $V_{D D}=5 V$. Nilai $R_{3}$ dan $C_{2}$ dihitung dengan Persamaan (1) dan divariasikan agar menghasilkan frekuensi penggal $100 \mathrm{~Hz} \leq f_{P} \leq 10 \mathrm{kHz}$. Sedangkan nilai $R_{1}, R_{2}$ dan $C_{1}$ adalah sama dengan bagian 4.1. Hasil pengukuran ditunjukkan Tabel 1.

Tabel 1. Hasil pengukuran karakteristik PLL dengan LPF orde 1

\begin{tabular}{|c|c|c|c|}
\hline$f_{\mathrm{P}}(\mathrm{Hz})$ & $V_{\text {ripple }}(\mathrm{V})$ & $f_{\mathrm{C}}(\mathrm{kHz})$ & $f_{\mathrm{L}}(\mathrm{kHz})$ \\
\hline 106 & $1,32 \sim 1,41$ & $8,5 \sim 9,5$ & $8,1 \sim 11,7$ \\
\hline 212 & $1,3 \sim 1,43$ & $8,3 \sim 9,8$ & $8,1 \sim 11,7$ \\
\hline 482 & $1,4 \sim 1,54$ & $8,25 \sim 10,5$ & $8,1 \sim 11,7$ \\
\hline 530 & $1,37 \sim 1,56$ & $8,25 \sim 10,7$ & $8,1 \sim 11,7$ \\
\hline 750 & $1,32 \sim 1,58$ & $8,2 \sim 11$ & $8,1 \sim 11,7$ \\
\hline 1.061 & $1,28 \sim 1,6$ & $8,2 \sim 11,2$ & $8,1 \sim 11,7$ \\
\hline 3.183 & $0,95 \sim 1,85$ & $8,2 \sim 11,3$ & $8,1 \sim 11,7$ \\
\hline 7.957 & $0,64 \sim 2,34$ & $8,15 \sim 11,53$ & $8,1 \sim 11,7$ \\
\hline 10.610 & $0,44 \sim 2,6$ & $8,1 \sim 11,58$ & $8,1 \sim 11,7$ \\
\hline
\end{tabular}

Pada pengukuran kedua, dilakukan pada PLL CD4046 dengan LPF orde 2 yaitu seperti Gambar 2 namun tapis diganti seperti Gambar 5. Parameter lain selain LPF adalah sama seperti pada pengujian pertama. Hasil pengukuran ditunjukkan Tabel 2.

Tabel 2. Hasil pengukuran karakteristik $P L L$ dengan $L P F$ orde 2

\begin{tabular}{|c|c|c|c|}
\hline$f_{\mathrm{P}}(\mathrm{Hz})$ & $V_{\text {ripple }}(\mathrm{V})$ & $f_{\mathrm{C}}(\mathrm{kHz})$ & $f_{\mathrm{L}}(\mathrm{kHz})$ \\
\hline 106 & $1,34 \sim 1,36$ & $9,3 \sim 10,4$ & $8,1 \sim 11.8$ \\
\hline 212 & $1,32 \sim 1,4$ & $9 \sim 10,6$ & $8,1 \sim 11,8$ \\
\hline 482 & $1,33 \sim 1,45$ & $8,7 \sim 11$ & $8,1 \sim 11,8$ \\
\hline 530 & $1,37 \sim 1,5$ & $8,6 \sim 11$ & $8,1 \sim 11,8$ \\
\hline 750 & $1,33 \sim 1,5$ & $8,4 \sim 11,3$ & $8,1 \sim 11,8$ \\
\hline 1.061 & $1,34 \sim 1,55$ & $8,1 \sim 11,6$ & $8,1 \sim 11,8$ \\
\hline 3.183 & $1,15 \sim 1,75$ & $8,1 \sim 11,6$ & $8,1 \sim 11,8$ \\
\hline 7.957 & $0,6 \sim 2,2$ & $8,1 \sim 11,7$ & $8,1 \sim 11,8$ \\
\hline 10.610 & $0,4 \sim 2,4$ & $8,1 \sim 11,8$ & $8,1 \sim 11,8$ \\
\hline
\end{tabular}


Tegangan riak ( $\left.V_{\text {ripple}}\right)$ di atas adalah rentang tegangan keluaran $L P F$ yang masuk ke $V C O$. Nilai tegangan riak makin besar untuk frekuensi penggal yang makin besar (baik untuk LPF orde satu maupun orde dua), hal ini dikarenakan makin banyak komponen frekuensi tinggi yang diloloskan. Makin besar tegangan riak, maka makin besar pula nilai capture range, sedangkan nilai lock range relatif tetap.

Nilai capture range bisa didekati dengan Persamaan 6, dimana $f c$ dalam persamaan tersebut adalah rentang (maksimum dikurangi minimum pada tiap baris) nilai $f_{\mathrm{c}}$ pada Tabel 1 dan 2 .

$$
2 f_{\mathrm{C}}=\sqrt{2 K_{\mathrm{O}} f_{\mathrm{P}} V_{\mathrm{DD}}}
$$

Dengan menggunakan rumus tersebut, nilai hasil perhitungan dan pengukuran cukup mendekati (ralat di bawah $10 \%$ ), jika $f_{c} / f_{p} \gg>1$. Nilai pengukuran capture range dengan $L P F$ orde dua lebih mendekati perhitungan, dibandingan dengan LPF orde satu, hal ini dikarenakan tegangan riaknya yang lebih kecil.

\section{Kesimpulan}

1. Semakin besar nilai frekuensi penggal pada tapis lolos bawah, maka semakin besar pula nilai capture range pada sistem PLL berbasis CD4046.

2. Dengan frekuensi penggal yang sama, nilai capture range tapis orde satu cenderung lebih besar dibandingkan tapis orde dua seperti yang digunakan di makalah ini, namun perbedaannya tidak signifikan.

\section{Daftar Pustaka}

[1] D.K. Morgan, CD4046B Phase-Locked Loop: A Versatile BuildingBlock for Micropower Digital and Analog Applications, Application Report, Texas Instrument, February 2003.

[2] G-C. Hsieh, J.C. Hung, "Phase Locked Loop Techniques - A Survey," IEEE Transaction on Industrial Electronics, vol 43, no 6, December 1996.

[3] D.R. Sulaiman, "Design and Analysis of a Second Order Phase Locked Loops (PLLs)," Proceedings of the 5th WSEAS International Conference on Telecommunications and Informatics, Istanbul, Turkey, May 27-29, 2006 (pp. 377-382)

[4] W. Li, J. Meiners, "Introduction to Phase-Locked Loop System Modeling," Analog Appications Journal, TI Incorporated, May 2000.

[5] D. Maksimovic, CMOS 4046 Phase Locked Loop [Online], http: //ecee.colorado.edu/ ecen4618/lab4 .pdf, diakses Desember 2015. 
